\title{
Grandparent-provided childcare and labor force participation of mothers with preschool children in Urban China
}

\author{
Fenglian $\mathrm{Du}^{1}$ (D) Xiao-yuan Dong ${ }^{2}$ Yinyu Zhang ${ }^{1}$
}

Received: 8 October 2018 / Accepted: 22 December 2018 / Published online: 21 January 2019

(c) China Population and Development Research 2019

\begin{abstract}
This paper investigates the effects of grandparent-provided childcare and the access to daycare services on the labor force participation of mothers with children under 7 years old in urban China. Using two-stage residual inclusion method, the analysis finds that grandparent-provided childcare and the access to daycare services both have strong positive effects on maternal labor force participation (MLFP). Specifically, having grandparent-provided childcare increases MLFP by 38-43\%, whereas having access to daycare services increases MLFP by 24-29\%. The analysis also finds that having a healthy grandmother is a significant determinant in whether grandparent-provided childcare is utilized and that the demand for grandparent-provided childcare is higher in localities in which daycare services for children under 3 years old are more expensive. These results indicate that grandparents, particularly grandmothers, play an important role in sustaining MLFP, particularly as the supply of publicly funded daycare programs is declining.
\end{abstract}

Keywords Grandparent-provided childcare - Labor force participation - Two-stage residual inclusion (2SRI) method

Fenglian Du

dufenglian@126.com

Xiao-yuan Dong

x.dong@uwinnipeg.ca

Yinyu Zhang

xue19890327@126.com

1 Inner Mongolian University, Hohhot, China

2 University of Winnipeg, Winnipeg, Canada 


\section{Introduction}

The massive entry of women with young children into the labor market in recent decades has drawn considerable scholarly attention to the interrelationships between maternal labor force participation (MLFP) and childcare choices. A large body of literature has emerged to investigate the interrelation between MLFP and access to state-sponsored or market-based formal childcare services, such as daycare services and public preschools. Studies find that increasing access to affordable formal childcare services has played an important role in enabling mothers with young children to participate in the labor force. ${ }^{1}$ Comparatively, the literature on the role of informal childcare-unregulated childcare provided by relatives, friends, neighbors, babysitters, or nannies is more limited. ${ }^{2}$

Informal childcare is a major form of non-parental childcare, and much of this informal childcare comes from grandparents, particularly grandmothers (Posadas 2012; Guzman 2004). ${ }^{3}$ Understanding the role of grandparents in providing childcare is essential to formulating effective policies addressing childcare needs and provision in light of rising maternal labor force participation (MLFP). While access to grandparent-provided childcare extends the choices that mothers with young children can make regarding work and family (Gray 2005), caring for grandchildren limits the choices of grandparents, as they might participate in paid work themselves or spend time on leisure activities instead of caring for grandchildren (Posadas and Vidal-Fernández 2012). Studies find that in many developed countries, grandparents who take care of grandchildren, particularly grandmothers, are less likely to have paid employment or tend to work fewer hours ${ }^{4}$ and that having a grandchild increases the grandparents' probability of retiring early. ${ }^{5}$ By helping young mothers circumvent the problem of having no access to affordable high-quality formal childcare services, however, the access to grandparents-provided childcare may delay the necessary policy action to address the undersupply of formal childcare services. ${ }^{6}$ Given the opportunity costs of caring for grandchildren, the availability of grandparents as caregivers should not be taken for granted. As women in those age groups

\footnotetext{
1 A selective list of studies includes Blau and Hagy (1998), Powell (2002) and Fitzpatrick (2010) for developed countries and Connelly et al. (1996), Lokshin et al. (2004) and Quisumbing et al. (2007) for developing countries.

2 The existing studies on this subject include Heckman (1974), Blau and Robins (1988), Brandon (2004), Posadas and Vidal-Fernández (2012), and Compton and Pollak (2014) for the United States, and Albuquerque and Passos (2010) and Zamarro (2011) for European countries.

${ }^{3}$ For instance, in the US, more than half of children under 2 years of age are in informal care and the care provided by grandparents accounts for more than half of such informal care (Posadas 2012). In the UK, more than one-quarter of children under 16 are regularly cared for by grandparents (Gray 2005). Approximately $50 \%$ of grandparents in the US and continental European countries provide some form of childcare (Guzman 2004; Hank and Buber 2009).

4 A selective list of studies on this topic includes Nguyen and Connelly (2014), Zamarro (2011), Rupert and Zanella (2018), Lilly et al. (2010), and Ho (2008).

5 See Lumsdaine (2014), Lewin-Epstein and Hochman (2013) and Van bavel and de Winter (2013).

${ }^{6}$ Connelly et al. (2004) find that in the United States, parents will use employer-sponsored childcare if it is available even if they have a relative who can provide childcare for them on an unpaid basis.
} 
that commonly include grandmothers become more educated and are characterized by more work experience, and as an aging population heightens the pressure to raise employment rates among older populations, the supply of grandparent-provided childcare may begin to decline. Inevitably, society must address the question of who is going to take care of children when both parents and grandparents are working.

In this paper, we use data from a nationally representative household survey for the 1991-2011 period to investigate how childcare provided by grandparents and daycare programs affect the LFP of mothers with children under 7 years old in urban China and compare the roles of the two types of non-parental childcare. China is a particularly interesting place to study the interrelationships between grandparents' childcare and maternal employment, given the country's ongoing social, economic and demographic transformations. Similar to the ex-socialist countries in Central and Eastern Europe and the former Soviet Union, China was able to achieve high female LFP by providing working mothers with paid maternity leave and subsidized nurseries and kindergartens during the Maoist era (1949-1976). However, publicly funded childcare services have been curtailed since China embarked on its transition to a market economy in the late 1970s (Liu et al. 2008). Many publicly funded childcare programs were shut down or transformed into service-for-fee commercial programs, while nurseries for children under 2 years of age virtually disappeared (Cook and Dong 2011; Liu et al. 2008). As formal childcare services became more expensive and inaccessible, Chinese working mothers increasingly sought support from their extended families and relatives.

In China, grandparents' caring for grandchildren has traditionally been a core component of family support (Chen et al. 2011). A study based on a recent national survey estimates that $58 \%$ of Chinese grandparents provided care for their grandchildren (Ko and Hank 2013). As in other countries, grandmothers in China are more likely than grandfathers to be engaged in childcare on a regular basis. In line with patrilineal norms, paternal grandparents are typically more involved in caring for grandchildren than maternal grandparents at least in part because significantly higher proportions of paternal grandparents co-reside with or live near their children (Chen et al. 2000, 2011). Nonetheless, an appreciable amount of grandparent-provided childcare takes place outside of co-residential households.

The high level of grandparents' involvement in childcare in urban China was a result of relatively low LFP rates among women in those age groups that commonly include grandmothers in the post-reform period (Hare 2016). China's retirement age is low by international standards, and urban Chinese women are typically retired between the ages of 50 and 55. During the public-sector restructuring in the late 1990s, mandatory early retirements were widely implemented, forcing many women in their late $40 \mathrm{~s}$ out of the labor market, and many older women had difficulty finding reemployment (Du and Dong 2009; Appleton et al. 2002). The low retirement age and challenging employment prospects for older women reduced the opportunity costs associated with grandparent-provided childcare particularly when affordable, high-quality formal childcare services were in short supply.

Studies have endeavored to investigate the impact of non-maternal childcare on the LFP of mothers of young children in urban China. Kilburn and Datar (2002) and Du and Dong (2013) find that the presence of childcare centers in an urban 
community has a positive effect on the LFP of mothers with preschool children. Song and Dong (2017) find that childcare costs have a strong negative effect on the LFP and childcare utilization of migrant mothers who co-reside with preschool children in urban areas and of non-migrant urban mothers as well. Chen et al. (2000, 2011) present evidence that co-residence with grandparents or having grandparents living nearby plays an important role in enabling mothers of preschool children to remain in the labor force. Maurer-Fazio et al. (2009) find that having a preschoolaged child has a negative effect on MLFP and that co-residence with grandparents has a positive effect on MLFP. These authors also find that the effects on MLFP of having young children and co-residence with grandparents increased over the 1990-2000 period.

The present paper seeks to make three key contributions to the literature. First, we use explicit information covering grandparent-provided childcare instead of relying on co-residence or proximity as a proxy for grandparent-provided childcare. Our approach produces more reliable estimates than the alternative, given that not all grandparents who co-reside or live nearby provide assistance to their adult children by caring for their grandchildren. Second, we compare the role and relative importance of grandparents' childcare with the services delivered through daycare centers. Third, we control for the potential endogenous relationship between childcare arrangements and maternal employment using an instrumental variable approach. Our paper adds to the small number of international studies seeking to establish a causal relation between grandparents' childcare and MLFP. ${ }^{7}$

This paper is structured as follows. The next section describes the data and sample that form the basis of our empirical analysis. The third section outlines the empirical methodology, and the fourth section presents the regression results. We conclude with a summary of our empirical results and a brief discussion of the policy implications of our study in Sect. 5.

\footnotetext{
${ }^{7}$ Albuquerque and Passos (2010) use a bivariate Probit model to estimate grandparent-provided childcare and MLFP in Europe. These authors find that the probability that a mother of preschool children will work increases by $12 \%$ if a grandparent cares for her youngest child. Zamarro (2011) applies a seemingly unrelated regression (SUR) model to estimate the effect of grandparent-provided childcare on MLFP in Europe. She finds evidence that grandparent-provided childcare has a positive effect on MLFP in the Netherlands and Greece. Posadas and Vidal-Fernandez (2012) apply an instrumental variable (IV) approach for the US. Using maternal grandmother's death as the IV for grandparent-provided childcare, these authors find that having access to grandparent-provided childcare increases the likelihood by $15-18 \%$ points that a mother with children under 13 years of age will participate in the labor force. Maurer-Fazio et al. (2009) apply the 2SRI method to estimate the LFP of Chinese women 25-50 years old. They use the proportion of households in the prefecture that have co-resident parents and/or parents-in-law, the mother's age, the husband's age, and a set of interactions between mother's age and her husband's age with higher order terms as IVs for co-residence with elderly parents. They find that coresidence with grandparents increases MLFP by $12 \%$.
} 


\section{Data and summary statistics}

The dataset used in this paper was derived from the China Health and Nutrition Survey (CHNS). ${ }^{8}$ We used pooled data from the 1991 to 2011 waves of the CHNS. In our analysis, we focused on urban mothers with a child aged 0-6 because the CHNS only asks childcare questions of those households with children under 7 years of age. After omitting observations with missing information, 2473 women-year observations comprised the final sample. The mothers in the sample were, on average, 30 years of age and had 9.7 years of schooling, and $84.4 \%$ of them participated in the labor force. Most of the working mothers in the sample (96\%) worked fulltime and, on average, worked $45 \mathrm{~h}$ per week.

In our analysis, we considered childcare arrangements for a mother's youngest child. Because of China's one-child policy, less than $5 \%$ of the mothers in the sample had more than one child aged 6 or younger. We examined the care provided by both co-residential and nonresidential grandparents. The information on childcare provided by the parents and co-residential grandparents was derived from the questions to all household members regarding whether they spent any time feeding, bathing, dressing, holding or watching children aged 6 years or younger who live in the household, and if so, how many hours they spent on childcare in the past week. From the responses we collected, we found that $30.5 \%$ of the children in the sample were cared for by co-residential grandmothers and $15.3 \%$ were cared for by coresidential grandfathers. In addition, the caregiving co-residential grandmothers and grandfathers, on average, spent 23.3 and $15.4 \mathrm{~h}$ per week on childcare, respectively. These results are in line with findings from other studies that grandmothers played a more important caregiving role than grandfathers for grandchildren (Chen et al. 2011). In comparison, the mothers, on average, spent $22.4 \mathrm{~h}$ per week on childcare, $1 \mathrm{~h}$ less than the time that average co-residential grandmothers spent.

We gathered the information on the care provided by nonresidential grandparents and daycare programs from the questions regarding whether children aged 6 or younger are cared for by people outside the household, and if so, where the child is cared for: in the household; in the home of the child's paternal grandparents; in the home of the child's maternal grandparents; in daycare programs or in the home of other relatives, and in how many houses the child was cared for by people outside the household in the past week. From the responses to these questions, we found that $7.9 \%$ of the children in our analysis were cared for in the home of paternal grandparents, $5.5 \%$ were cared for in the home of maternal grandparents, and $22.9 \%$ were cared for in daycare programs. Because some mothers used more than one type of care provided outside the household, we do not know how much time a child was

\footnotetext{
8 The CHNS is jointly sponsored by the Carolina Population Center at the University of North Carolina at Chapel Hill, the Institute of Nutrition and Food Hygiene of China and the Chinese Academy of Preventive Medicine. The survey covers a total of 15 Chinese provinces and province-equivalent municipalities, including Beijing, Chongqing, Guizhou, Guangxi, Heilongjiang, Henan, Hubei, Hunan, Jiangsu, Liaoning, Shaanxi, Shanghai, Shandong, Yunnan and Zhejiang. Each survey covers approximately 4000 households and 14,000 individuals in both urban and rural areas. Detailed information about the CHNS is available at its website, http://www.cpc.unc.edu/china/home.html.
} 
Table 1 Childcare arrangements for children aged $0-6$, by maternal work status Source: Statistics presented in all tables are derived from CHNS

\begin{tabular}{|c|c|c|c|c|}
\hline & \multicolumn{2}{|c|}{ Non-parental care } & \multicolumn{2}{|c|}{ Parental care } \\
\hline & Daycare & $\begin{array}{l}\text { Grandpa- } \\
\text { rental care }\end{array}$ & Mother & Father \\
\hline \multicolumn{5}{|c|}{ All mothers (observations $=2473$ ) } \\
\hline$\%$ using this type of care & 22.9 & 48.0 & 94.7 & 42.4 \\
\hline \multicolumn{5}{|l|}{ Child aged $0-2$} \\
\hline$\%$ using this type of care & 8.0 & 63.3 & 97.1 & 52.0 \\
\hline \multicolumn{5}{|l|}{ Child aged 3-6 } \\
\hline$\%$ using this type of care & 31.3 & 39.2 & 93.4 & 36.9 \\
\hline \multicolumn{5}{|c|}{ Working mothers (observations $=2087$ ) } \\
\hline$\%$ using this type of care & 24.8 & 50.0 & 93.8 & 42.8 \\
\hline \multicolumn{5}{|c|}{ Non-working mothers (observations $=386$ ) } \\
\hline$\%$ using this type of care & 12.2 & 37.1 & 100.00 & 40.2 \\
\hline
\end{tabular}

Some mothers used more than one type of care, and therefore the sum of the percentages is more than $100 \%$. The use of daycare and grandparental care is not mutually exclusive, and some parents used both types of care. Care provided by relatives and nannies is omitted because very few children received this type of care

cared for by a specific type of outside caregivers. For all children who were cared for by outside caregivers, the average weekly hours of childcare was $43.7 \mathrm{~h}$. In our analysis, grandparent-provided childcare is defined as that care provided by co-residential grandparents or in the home of paternal or maternal grandparents, whereas daycare programs include nurseries, kindergartens and preschools.

Table 1 provides a summary of childcare arrangements for children aged 0-6 by child age and mothers' work status. The table shows that most mothers provided childcare, although working mothers had a lower childcare participation rate than non-working mothers (93.4\% versus 100\%). An appreciable proportion of fathers participated in childcare, and the percentage of paternal childcare was slightly higher for working mothers than for nonworking mothers ( $42.8 \%$ versus $40.2 \%$ ). The use of grandparent-provided childcare was much more common than the use of daycare programs, as it is apparent that the proportion of children cared for by grandparents more than doubled that of children enrolled in daycare programs (48\% versus $22.9 \%$ ), and more than half of the children who were enrolled in daycare programs were also cared for by grandparents. As expected, the proportion of infants and toddlers cared for in daycare programs was much lower than that of preschoolers, whereas the opposite patterns appear for the allocation of grandparent care over the two age groups. In addition and as expected, working mothers were more likely than nonworking mothers to use daycare and grandparent-provided childcare. Although nonworking mothers have less need for non-parental childcare than working mothers, $12.2 \%$ of the nonworking mothers enrolled their children in daycare programs, 
Table 2 Trends of fathers and mothers' labor force participation and non-parental childcare

\begin{tabular}{lllllll}
\hline \multirow{2}{*}{ Year } & \multicolumn{2}{l}{ Labor force participation rate $(\%)$} & & \multicolumn{2}{l}{ Non-parental childcare (\%) } \\
\cline { 2 - 3 } & Father & Mother & Gender gap & & Daycare & Grandparents \\
\hline 1991 & 99.1 & 90.3 & 8.8 & & 26.1 & 39.9 \\
1993 & 97.6 & 90.1 & 7.5 & & 21.5 & 38.8 \\
1997 & 97.4 & 91.4 & 6.1 & & 22.0 & 54.6 \\
2000 & 96.9 & 87.5 & 9.4 & & 25.8 & 53.1 \\
2004 & 91.4 & 76.6 & 14.8 & & 22.5 & 49.3 \\
2006 & 92.3 & 76.9 & 15.4 & & 17.4 & 56.4 \\
2009 & 91.0 & 72.0 & 19.0 & & 20.9 & 51.2 \\
2011 & 88.3 & 74.9 & 13.3 & & 22.2 & 55.6 \\
Observations & 2473 & 2473 & - & & 2473 & 2473 \\
\hline
\end{tabular}

The gender gap is the difference between fathers' and mothers' labor force participation rates. Childcare provided by grandparents includes childcare services provided by both co-residential and non-residential grandparents. Daycare and grandparent childcare are not mutually exclusive, as some parents use both types of services

and $37.1 \%$ of these mothers reported having grandparents care for their children. ${ }^{9}$ Nonworking mothers may use non-parental childcare for reasons such as early education for children, allowing children to spend time with grandparents or giving themselves the time to attend to domestic chores or to enjoy their leisure time.

Table 2 presents the trends of maternal and paternal LFP and non-parental childcare arrangements. From 1991 to 2011, both paternal and maternal LFP were on a steady decline, from 99.1 to $88.3 \%$ for fathers and from 90.3 to $74.9 \%$ for mothers. The decline in LFP might be attributed to the expansion of post-secondary education, the increase in income levels in the post-reform period and public-sector restructuring. Nevertheless, MLFP decreased more than paternal LFP and the gender LFP gap widened from 8.8 to $13.3 \%$. Since 2000 , more than $70 \%$ of mothers with children under the age of 7 continued to participate in the labor force, regardless of the expanding gender disparity. Such relatively high MLFP would have been impossible without a high degree of grandparent engagement in childcare, particularly when the declining supply of publicly subsidized daycare programs is taken into account. Indeed, during the period under investigation, the proportion of children who were enrolled in daycare programs decreased from 26.1 to $22.2 \%$, whereas the proportion of children cared for by grandparents increased from 39.9 to $55.6 \%$.

As discussed in the introduction, the role of grandparents as caregivers in enabling MLFP is a major component of intergenerational relations for Chinese households. As Table 3 shows, $60.4 \%$ of the co-residential grandmothers in the sample

\footnotetext{
9 Based on the information on co-residential grandparents, grandparents spent more time caring for the children of working mothers than those of nonworking mothers. For instance, the average weekly hours of childcare provided by grandmothers and grandfathers were, respectively, 24 and $16 \mathrm{~h}$ for the children of working mothers and 18 and $10-11 \mathrm{~h}$ for those of nonworking mothers.
} 
Table 3 Main characteristics of co-residential grandparent caregivers

\begin{tabular}{lcc}
\hline & Grandmothers & Grandfathers \\
\hline $\begin{array}{l}\text { \% of all co-residential grand- } \\
\text { mothers or grandfathers }\end{array}$ & 60.4 & 36.8 \\
$\begin{array}{l}\text { Mean years of schooling } \\
\text { Labor force participation (\%) }\end{array}$ & 4.4 & 7.1 \\
Mean age & 23.0 & 34.1 \\
Age distribution (\%) & 58.3 & 60.4 \\
Under 49 & & \\
50-54 & 9.2 & 4.5 \\
55-59 & 22.7 & 14.3 \\
60-64 & 28.6 & 28.8 \\
65 and older & 21.4 & 26.5 \\
Total & 18.1 & 25.9 \\
Observations & 100.0 & 100.0 \\
\hline
\end{tabular}

and $36.8 \%$ of the co-residential grandfathers were engaged in childcare. The LFP of grandparent caregivers was low at $23 \%$ for grandmothers and $34.1 \%$ for grandfathers. Grandparents' involvement in childcare appears economically rational, given the lower opportunity cost of grandparents caring for children compared with the parents. Indeed, the average years of schooling were 4.4 year for grandmother caregivers and 7.1 years for grandfather caregivers; by contrast, the average years of schooling were 9.7 years for the mothers and 10 years for fathers. Notably, $82 \%$ of the grandmother caregivers and $74 \%$ of the grandfather caregivers were under the age of 65 years - the standard age of retirement in most developed countries. The availability of grandparents as caregivers would fall markedly if the retirement age were raised to the level of international norms. In the remainder of the paper, we investigate how having grandparents care for children and daycare utilization may affect MLFP.

\section{Empirical methodology}

We estimate the effects of grandparent-provided childcare and daycare services on the LFP of mothers with a child under 7 years old using the following regression model:

$$
\mathrm{MLFP}=1\left[\beta_{0}+\beta_{1} \mathrm{GC}+\beta_{2} \mathrm{DC}+\lambda^{\prime} \mathrm{X}+\mathrm{u}>0\right],
$$

where MLFP is a dummy variable that is equal to 1 if the mother is in the labor force and 0 otherwise, GC is a dummy variable that is equal to 1 if the mother's child is cared for by grandparents and 0 otherwise, and DC is a dummy variable that is equal to 1 if the child is enrolled in a daycare and 0 otherwise. $X$ is a vector of covariates that includes mother's education, age and its squared term, father's education and age, non-earned income, age and sex of the youngest child, number of boys aged 7-14 and number of girls aged 7-14, average wages of male and female workers in 
the applicable community, regional fixed effects and time dummy variables; ${ }^{10}$ and $\mathrm{u}$ is the error term. The Greek letters are the parameters to be estimated. We limit the empirical analysis to MLFP and do not analyze maternal labor hour supply because the vast majority of working mothers under analysis worked fulltime and their working hours were determined, to a large extent, by their employers.

The main empirical concern of Eq. (1) is that grandparent-provided childcare (GC) and daycare (DC) enrolment may be endogenous due to unobserved heterogeneity or because a mother's decisions regarding LFP and childcare arrangements tend to be made simultaneously. Due to unobserved family and community norms of parenting and intergenerational relationship and individual and household circumstances, grandparent-provided childcare is often driven by a variety of reasons from concerns about the physical wellbeing of grandchildren and values involving fostering intergenerational bonds to the childcare needs of working mothers. As noted above, there is an appreciable proportion of non-working mothers in our sample who reported having grandparents look after their children. A failure to disentangle the causes of grandparents' involvement in childcare for non-working mothers from those for working mothers would create a downward bias when estimating the effects of grandparent-provided childcare on MLFP. Our analysis addressed this problem by using an IV approach. Because GC and DC are binary variables, the estimates of the conventional two-stage probit regressions are inconsistent (Terza et al. 2008). Therefore, we estimate Eq. (1) using the two-stage residual inclusion (2SRI) method. The first-stage of 2SRI is to estimate the reduced-form equations of GC and DC using probit regressions and obtains the residuals of two reduced-form equations. The second stage is to add the residuals to the structural equation in (1) and estimate the augmented structural equation with probit regressions. The 2SRI estimates are consistent.

The IVs for GC consist of four dummy variables that indicate whether the mother has a healthy mother in-law, healthy father in-law, healthy father and healthy mother. A grandparent is considered "healthy" if he/she is alive and does not need to be taken care of by other people. Having a healthy grandparent is indicative of the availability of grandparent-provided childcare, particularly for working mothers. Given that the vast majority of working mothers in China work on a fulltime basis, the childcare provided by grandparents that meets the needs of working mothers is expected to be more physically demanding and more reliable than the care performed by grandparents for children of non-working mothers. Working mothers could not rely on those grandparents who need care themselves to meet their childcare need, although the latter may nonetheless look after grandchildren occasionally or spend time watching or playing with grandchildren to foster a bond with their grandchildren. Thus, using the variables that represent whether a mother has access to a healthy grandparent as the IVs for GC allows us to differentiate the grandparent care that enables MLFP from that care performed for children of non-working

\footnotetext{
10 Since grandparent-provided childcare is directly accounted for in the model, we omit the variables for adult composition of the household. Grandparent-provided childcare is highly correlated with the presence of women in those age groups commonly containing grandmothers.
} 
mothers. The variables of having healthy grandparents should be correlated with GC but not with MLFP when the effect of GC is controlled for. The IVs for DC include two variables at the community level, i.e., distance to the nearest DC for children aged 0-2 and aged 3-6, and two variables at the city level, i.e., median prices of DC for the same two groups of children. These variables are indicative of the accessibility and affordability of DC services and are thus assumed to be correlated with DC utilization but uncorrelated with MLFP when the variable of DC is included in the structural equation. One concern about the exogeneity assumption for the IVs for DC is that certain unobserved community characteristics may be correlated jointly with a high MLFP, high DC accessibility and high DC prices. To address this concern, we estimate two versions of Eq. (1), with one controlling for province-fixed effects and one controlling for community-fixed effects. The latter approach removes time-invariant community characteristics that may lead to potentially simultaneous relationships between DC programs and MLFP.

The covariate variables and IVs are defined as follows. Parents' education is measured by years of schooling. Non-earned income is the sum of the husband's earnings and the family's non-labor income measured in yuan per month. Average wages of male and female workers in a community are measured in yuan per day. The distance to the nearest DC is measured in $\mathrm{km}$. The prices of DC programs are measured in yuan per month. All monetary variables are discounted by the urban consumer price index from the CHNS in 2011, and all are in log form. The summary statistics of the explanatory variables for mothers' work status are presented in the Appendix 1.

\section{Results}

Table 4 depicts probit estimates of the first-stage regressions for GC and DC. The first two columns present the estimates for the specifications of controlling for province-fixed effects and the last two columns present the estimates for specification of controlling for community-fixed effects. The estimates for the first-stage regressions caste light on the main determinants of GC and DC utilization. Before discussing the estimates of IVs, we examine the covariates of the first-stage equations. For both specifications, the child's age is a highly significant determinant of the probability that GC or DC is used; it is inversely correlated with the probability of using GC and positively with the probability of using DC. Care provided by grandparents is considered a better substitute for maternal care than DC programs for infants and toddlers, whereas the opposite is true for preschoolers. The mother's education is another significant determinant of the probability of using each type of childcare and is positively correlated with the probability that the mother uses GC or DC. As we would expect, more-educated mothers have a greater need for non-maternal childcare since they are more likely to participate in the labor market. Notably, the father's education is statistically insignificant for both GC and DC, although the father's age has a significant negative effect on the probability of using GC. The finding that grandparents are more inclined to take care of children for sons of younger age is perhaps because young couples are less experienced with parenting 


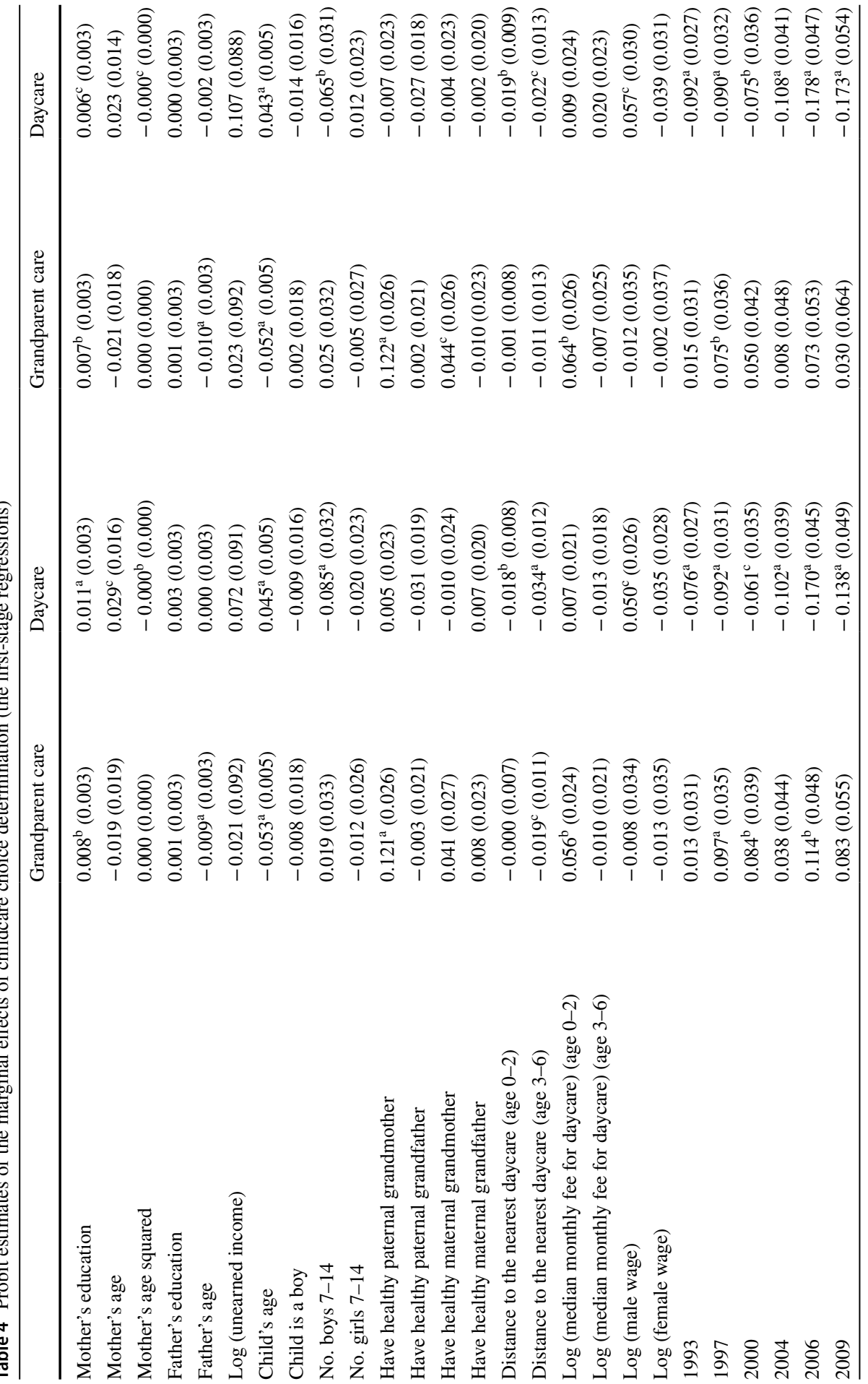




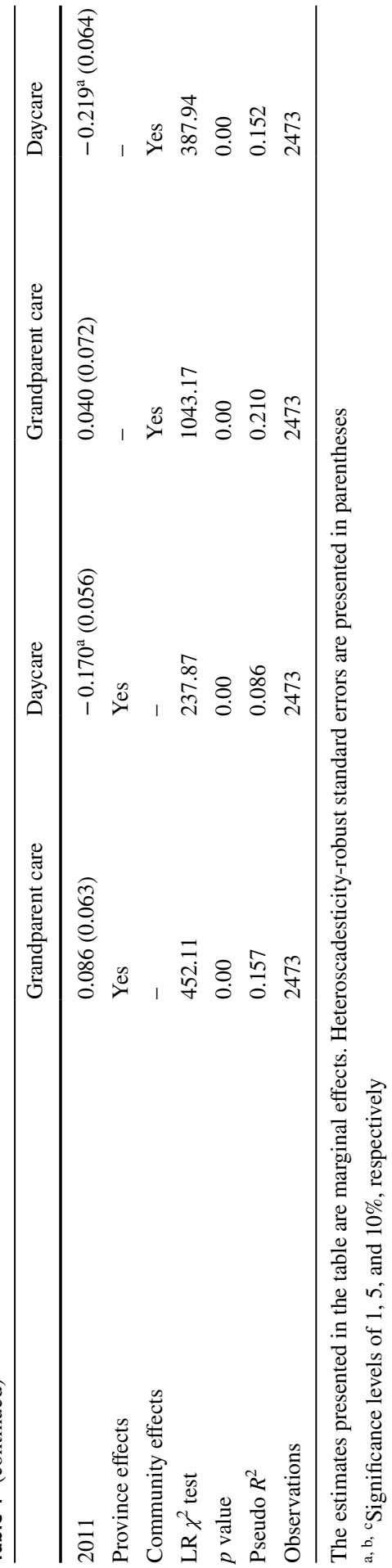


and therefore require more help from their parents. Importantly, the estimates of year dummy variables exhibit a steady decline in DC utilization and a rising trend for GC during the period from 1991 to 2011.

With respect to the estimates of IVs for GC and DC, we begin the discussion with the GC equations. For the specifications with province-fixed effects, the variable of having a healthy paternal grandmother is the only significant variable among the four IVs for GC, which indicates that having a healthy paternal grandmother increases the probability of using GC by $12 \%$. For specifications with community-fixed effects, the variables of having a healthy paternal or a maternal grandmother are both significant, and the estimates show that having a healthy paternal or a maternal grandmother increases the probability of using GC by 12.2 and $4.4 \%$, respectively. Having a healthy paternal grandmother appears more important than having a healthy maternal grandmother for having access to GC. For both specifications, the variable of having a healthy paternal or a maternal grandfather has no significant effect on the use of GC, which implies that the care provided by grandfathers is not as physically demanding as the care provided by grandmothers. Some grandfathers who were providing childcare may do so just for the sake of spending time with grandchildren. These results support that GC is gendered and remains shaped by patriarchal norms in Chinese society. For both specifications, the price of DC for children 0-2 years old has a significant positive effect on the probability of using GC, whereas the price of DC for children 3-6 years old is statistically insignificant. These results support the notion that grandparents are a good substitute for DC for infants and toddlers but not for DC for preschoolers. With respect to the IVs in the first-stage regressions for DC, the distance to the nearest DC for children in both age groups is statistically significant and is inversely correlated with the probability of using DC. However, the prices of DC for children in two age groups are statistically insignificant. The lack of access to DC appears a more severe constraint on DC utilization than high DC prices. In terms of IV validity, we have at least one IV that is strongly correlated with the instrumented variable in the first-stage regressions.

Table 5 presents probit and 2SRI estimates for MLFP structural equations, with the specification for controlling for province-fixed effects in the first three columns and the specification for controlling for community-fixed effects in the last three columns. The table shows that the estimates of the two specifications are very similar. To check the robustness of the 2SRI estimates, we include two childcare variables in the regressions incrementally, where the first includes GC alone while controlling for the distance to and the prices of DC and where the next adds DC to the regression while excluding the variables on DC distance and prices, which are used as IVs for DC in this regression. The Hausman test statistics presented at the bottom of Table 5 reject the null hypothesis that GC (or DC) is exogenous. The over-identifying restrictions tests, also presented at the bottom of the table, cannot reject the null hypothesis that the IVs for GC (or DC) are uncorrelated with the error term of the structural equation for MLFP. Based on these diagnostic tests, the 2SRI estimates are consistent, whereas the probit estimates are not.

We first investigate the estimates of GC and DC - the variables of primary interest. The probit estimates show that both GC and DC are positively correlated with the probability of MLFP and the correlations are highly significant. Numerically, 


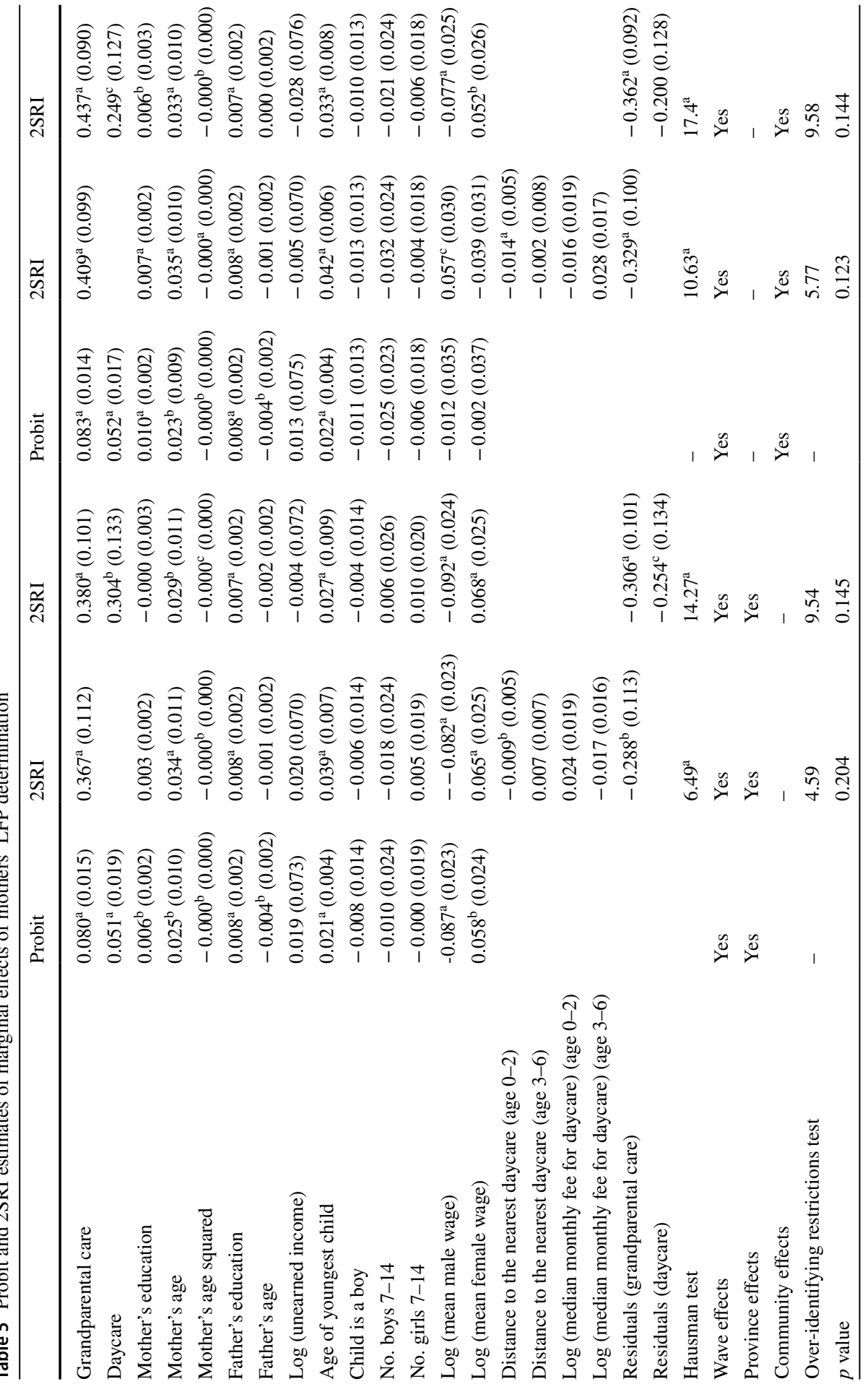




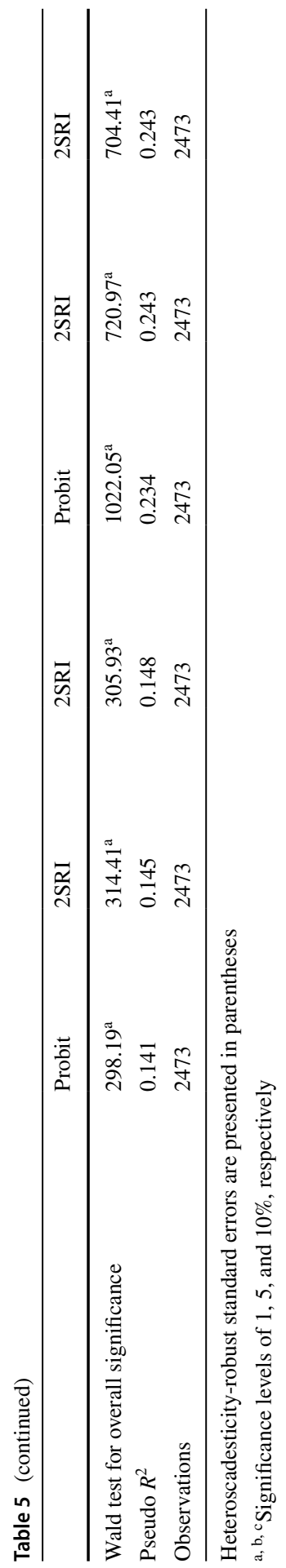


access to GC is associated with an $8 \%$ increase in the probability of MLFP; whereas using DC is associated with a $5 \%$ increases in the probability of MLFP. GC has a stronger enabling effect on MLFP than DC in part because it is more difficult for mothers to combine paid work with caregiving for infants and toddlers than it is for caring for preschoolers, and GC is more widely used for younger children than DC.

Turning to the 2SRI estimates, we find that the estimates of grandparent care in all four regressions have a positive sign and are highly significant and that the size of these estimates is markedly larger than that of the probit estimates. Specifically, the 2SRI estimates show that using GC increases the probability of MFLP by $36.7-43.5 \%$ points, four to five times that of the probit estimates. For both specifications, the size of the GC estimates increases slightly when the DC variable is added to the regression. Regardless of whether or not the regression includes the DC variable, the estimates of GC are higher for specifications with community-fixed effects than for specifications with province-fixed effects. For all 2SRI regressions, the residuals of GC have a negative sign and are highly significant. This result supports the proposition that the GC variable is endogenous and that the part of the variations in GC that is uncorrelated with access to the health status of grandparents is negatively correlated with the probability of MLFP. ${ }^{11}$ By controlling for this negative correlation between GC and MLFP due to unobserved individual, family and community characteristics, the 2SRI regressions generate an estimate of the GC effect that is much larger than the probit estimates.

Comparatively, our 2SRI estimates of the GC effect are greater than those obtained in previous studies. For instance, Maurer-Fazio et al. (2009) estimate that, in China, co-residence with women in the age group that commonly includes grandmothers increases the LFP of married women between 25 and 50 years of age by $12 \%$. This estimate is lower than ours for two reasons. First, those authors did not consider that not all co-residential grandparents provided care for children and coresidence with grandparents who require care themselves may lower the LFP of their daughters or daughter in-laws. Second, our analysis focuses on mothers with a child aged 6 or younger, whereas the scope of Maurer-Fazio et al. (2009) is broader and also includes childless women and women with school-aged children. Hence, having access to non-maternal childcare for the LFP of a typical woman in their sample is not as essential as for a typical woman in our sample. Using maternal grandmother's death as an IV, Posadas and Vidal-Fernandez (2012) find that having access to GC increases MLFP in the US by 15-18\%. Compton and Pollak (2014) find that living in close proximity to their mother or their mothers-in-law increases the LFP of married American women with young children by 4-10\% points. Our estimates show that GC has a stronger enabling effect on MLFP in China than in the US. Part of the difference may be attributable to the fact that compared with American

\footnotetext{
11 For instance, households with strong concerns about the physical wellbeing of children may treat raising a child as a joint mission between a nonworking mother and grandparents. A negative correlation between grandparent-provided childcare and MLFP may also be found in those communities in which both young and middle-age women have low LFP, enabling grandmothers to be involved in childcare even when the mother is not participating in the labor force.
} 
women, Chinese women are more constrained by limited flexibility in work arrangements, particularly with regard to wage employment, and part-time jobs are scarcer in China than in the US (Sheng and Settles 2006). Thus, without access to GC, it would be more difficult for Chinese mothers to participate in the labor force than for their American counterparts.

Regarding DC effects, the 2SRI estimates show that the LFP of mothers who use DC is 24.0-29.5\% higher than that of mothers who do not use DC, and the difference is statistically significant. As with GC, the 2SRI estimates for DC are much larger than the probit estimates. Compared with GC, the effects of DC are smaller, 0.295 versus 0.382 for the specification with province-fixed effects and 0.240 versus 0.435 for the specifications with community-fixed effects. The estimates also show that the residuals of the first-stage equations for DC are negatively correlated with MLFP for both specifications, although the estimate is significant only for specifications with province-fixed effects. Thus, the evidence for the endogeneity of DC is not as strong as that for GC. Nevertheless, unobserved personal tastes or family circumstance might create a negative association between MLFP and DC utilization. For instance, mothers who have a strong preference for leisure or who have a great care responsibility for sick or disabled family members may not participate in the labor force but may nonetheless enroll their children in DC.

We conclude this section with brief comments on the covariates of the structural equation presented in Table 5. We focus on the 2SRI estimates, since the probit estimates are inconsistent. The estimates show that the mother's education has a positive effect on MLFP but that the effect is significant only for the specification with community-fixed effects. The estimates of the mother's age variables depict an inverted U-shaped relation between the mother's age and MLFP, and the estimates are significant for both specifications. The father's education also has a positive sign and is statistically significant for both specifications. Moreover, the age of the youngest child has a significant positive effect on MLFP. Regarding community characteristics, we find that the probability of MLFP is lower in those communities with higher male wages but higher in those communities with higher female wages. For specifications that only includes GC, the distance to the nearest DC for children 0-2 years of age has a significant negative effect on MLFP, whereas the distance to DC for older children is statistically insignificant. This result indicates that the mother's LFP is more constrained by the lack of access to DC for younger children. It is convincing that all the estimates discussed above accord well with economic intuitions.

\section{Conclusions}

China's economic transition has sharply reduced the supply of publicly funded DC services and amplified families' needs for informal childcare arrangements. As a result, grandparents caring for grandchildren became a common feature of Chinese working families with young children. In this paper, we document the trends of GC 
and DC utilization and estimate the impacts of the two types of childcare on MLFP in post-reform urban China. We find that during the period from 1991 to 2011, DC utilization rates were on a steady decline, whereas the proportion of children cared for by grandparents rose markedly. For the period as a whole, the utilization rate of GC was twice as large as that of DC. Our regression analysis shows that GC and DC both have a strong positive effect on MLFP and that the effect of GC is noticeably larger than that of DC. The analysis also finds that having a healthy grandmother is a significant determinant of access to GC, that families' demand for GC is higher in those localities in which DC for children under the age of 3 are more expensive, and that the lack of access to DC for young children is a significant deterrent to MLFP.

The findings reported in the present paper underscore the important role that grandparents played in filling the gap created by the state's withdrawal from providing childcare and sustaining MLFP in reform era urban China. However, studies show that caring for grandchildren decreases the LFP of women aged between 45 and 64 years old (Wang and Zhang 2018; Mao et al. 2018), and therefore hinders their ability to accumulate wealth for old age. Thus, grandparents' involvement in childcare does not provides a solution to the work-family conflict Chinese women face from a life-course perspective. The on-going demographic transition toward an aging society is likely to further intensify the pressure on women in playing their due roles as caregivers and income earners in urban China. To improve the labor supply and ease the pressure on pension programs, a gradual increase of the retirement age is inevitable, which will reduce the supply of non-parental childcare to working families. There is a serious conflict between the objectives of the two policies, given the important caregiving role that younger grandparents play. To minimize "potential childcare deficits", childcare needs and provision should be factored into the formulation of public policies on fertility, employment and retirement. Retirement age policies should be flexible, allowing women and men to decide the timing of retirement based on family care needs and employment prospects. Familyfriendly workplace arrangements, such as flexible work arrangements and part-time jobs, should be encouraged so that both parents and grandparents are able to care for children while participating in the labor market. Most importantly, the State should play a larger role in funding and regulating DC programs to make high-quality DC programs more affordable and more accessible to Chinese families.

Funding The work was carried out with the aid of a grant from the National Natural Science Foundation of China (Grant no. 71373111) and a grant from the International Development Research Center of Canada (Project no. 107579). We also benefit greatly from the comments and suggestions of Margaret Maurer-Fazio on an earlier version of the paper. 


\section{Appendix}

\section{See Table 6.}

Table 6 Summary statistics of variables included in regressions

\begin{tabular}{|c|c|c|c|}
\hline Variables & All mothers & $\begin{array}{l}\text { Mothers in labor } \\
\text { force }\end{array}$ & $\begin{array}{l}\text { Mothers not in } \\
\text { labor force }\end{array}$ \\
\hline Mother in labor force $($ yes $=1$, no $=0)$ & $0.844(0.363)$ & 1.000 & 0.000 \\
\hline Grandparent care $($ yes $=1$, no $=0)$ & $0.480(0.500)$ & $0.500(0.500)$ & $0.370(0.484)$ \\
\hline Daycare $($ yes $=1$, no $=0)$ & $0.228(0.420)$ & $0.248(0.432)$ & $0.122(0.327)$ \\
\hline Mother's education (year) & $9.710(3.702)$ & $9.780(3.782)$ & $9.337(3.213)$ \\
\hline Mother's age (year) & $30.022(4.767)$ & $29.985(4.570)$ & $30.220(5.722)$ \\
\hline Father's education (year) & $10.019(3.376)$ & $10.117(3.392)$ & $9.487(3.240)$ \\
\hline Father's age (year) & $32.091(5.370)$ & $31.965(5.129)$ & $32.775(6.487)$ \\
\hline Log (unearned income ${ }^{a}$ ) & $0.136(0.127)$ & $0.131(0.122)$ & $0.163(0.147)$ \\
\hline Age of youngest child & $3.351(1.907)$ & $3.432(1.874)$ & $2.909(2.023)$ \\
\hline Child is boy & $0.544(0.498)$ & $0.542(0.498)$ & $0.554(0.498)$ \\
\hline No. males age $7-14$ & $0.092(0.306)$ & $0.093(0.311)$ & $0.085(0.280)$ \\
\hline No. females age $7-14$ & $0.150(0.385)$ & $0.149(0.385)$ & $0.150(0.386)$ \\
\hline $\log \left(\right.$ mean male wage $\left.{ }^{\mathrm{b}}\right)$ & $3.217(0.718)$ & $3.165(0.720)$ & $3.495(0.638)$ \\
\hline $\log \left(\right.$ mean female wage $\left.^{\mathrm{a}}\right)$ & $2.994(0.717)$ & $2.954(0.712)$ & $3.208(0.707)$ \\
\hline Have healthy paternal grandmother $($ yes $=1$, no $=0$ ) & $0.817(0.387)$ & $0.825(0.380)$ & $0.775(0.418)$ \\
\hline Have healthy paternal grandfather $($ yes $=1$, no $=0$ ) & $0.669(0.471)$ & $0.673(0.469)$ & $0.645(0.497)$ \\
\hline Have healthy maternal grandmother $($ yes $=1$, no $=0$ ) & $0.839(0.368)$ & $0.850(0.358)$ & $0.780(0.415)$ \\
\hline Have healthy maternal grandfather $($ yes $=1$, no $=0$ ) & $0.746(0.435)$ & $0.7540 .431)$ & $0.705(0.457)$ \\
\hline Distance to the nearest daycare age $0-2(\mathrm{~km})$ & $0.832(1.500)$ & $0.781(1.417)$ & $1.105(1.868)$ \\
\hline Distance to the nearest daycare age $3-6(\mathrm{~km})$ & $0.492(1.066)$ & $0.484(1.054)$ & $0.537(1.129)$ \\
\hline $\log$ (median monthly fee for daycare) age $0-2^{\mathrm{d}}$ (yuan) & $4.862(0.862)$ & $4.834(0.849)$ & $5.018(0.915)$ \\
\hline $\log$ (median monthly fee for daycare) age $3-6^{\mathrm{d}}$ (yuan) & $4.703(0.962)$ & $4.666(0.961)$ & $4.902(0.946)$ \\
\hline Observations & 2473 & 2087 & 386 \\
\hline
\end{tabular}

${ }^{a}$ Unearned income includes father's labor earnings and family non-labor income measured in 10,000 yuan per month

${ }^{\mathrm{b}}$ Female wages are the mean wages of female workers in a community measured in yuan per day

${ }^{\mathrm{c}}$ Male wages are the mean wages of male workers in a community measured in yuan per day

${ }^{\mathrm{d}}$ The prices of daycare programs are the childcare centers for each of the two age groups in a city or a county measured in yuan per month. Standard deviations are presented in parentheses

\section{References}

Albuquerque, P., Passos, J. (2010). Grandparents and women's participation in the labor market. Working papers of Department of Economics at Technical University of Lisbon, WP16/2010/DE/SOCIUS/ CEMAPRE.

Appleton, S., Knight, J., Song, L., \& Xia, Q. (2002). Labor retrenchment in China: Determinants and consequences. China Economic Review, 13, 252-275.

Blau, D. M., \& Hagy, A. P. (1998). The demand for quality in child care. Journal of Political Economy, 106, 104-139. 
Blau, D. M., \& Robins, P. K. (1988). Child care costs and family labor supply. Review of Economics and Statistics, 70(3), 374-381.

Brandon, P. (2004). The child care arrangements of preschool-age children in immigrant families in the United States. International Migration, 42(1), 65-87.

Chen, F., Liu, G., \& Mair, C. A. (2011). Intergenerational ties in context: Grandparents caring for grandchildren in China. Social Forces, 90(2), 571-594.

Chen, F., Short, S. E., \& Entwisle, B. (2000). The impact of grandparental proximity on maternal childcare in China. Population Research and Policy Review, 19(6), 571-590.

Compton, J., \& Pollak, R. A. (2014). Family proximity, childcare, and women's labor force attachment. Journal of Urban Economics, 79(7), 2-90.

Connelly, R., Deborah, S., \& Willis, R. A. (2004). The value of employer-sponsored child care to employees. Industrial Relations, 43(4), 759-792.

Connelly, R., DeGraff, D. S., \& Levison, D. (1996). Women's employment and child care in Brazil. Economic Development and Culture Change, 44, 619-656.

Cook, S., \& Dong, X. (2011). Harsh choices: Chinese women's paid work and unpaid care responsibilities under economic reform. Development and Change, 42(4), 947-965.

Du, F., \& Dong, X.-Y. (2009). Why do women have longer durations of unemployment than men in postrestructuring Urban China? Cambridge Journal of Economics, 33(2), 233-252.

Du, F., \& Dong, X. (2013). Women's employment and childcare choices in Urban China during the economic transition. Economic Development and Cultural Change, 62(1), 131-155.

Fitzpatrick, M. D. (2010). Preschoolers enrolled and mothers at work: The effects of Universal Prekindergarten. Journal of Labor Economics, 28(1), 51-85.

Gray, A. (2005). The changing availability of grandparents as carers and its implications for childcare policy in the UK. Journal of Social Policy, 34, 557-577.

Guzman, L. (2004). Grandma and grandpa taking care of the kids: Patterns of involvement (Child Trends Research Brief 2004-017). https://www.childtrends.org/publications/grandma-and-grandpa-takin g-care-of-the-kids-patterns-of-involvement.

Hank, K., \& Buber, I. (2009). Grandparents caring for their grandchildren: Findings from the 2004 survey of health, ageing and retirement in europe. Journal of Family Issues, 30, 53-73.

Heckman, J. J. (1974). Effects of child care programs on women's work effort. Journal of Political Economy, 82, 136-163.

Ho, C. W. D. (2008). Exploring the definitions of quality early childhood programmes in a market-driven context: Case studies of two Hong Kong preschools. International Journal of Early Years Education, 16(3), 223-236.

Lewin-Epstein, N., \& Hochman, O. (2013). Determinants of early retirement preferences in Europe: The role of grandparenthood. International Journal of Comparative Sociology, 54(1), 29-47.

Lilly, M. B., Laporte, A., \& Coyte, P. C. (2010). Do they care too much to work? The influence of caregiving intensity on the labour force participation of unpaid caregivers in Canada. Journal of Health Economics, 29(6), 895-903.

Liu, B., Yongying, Z., \& Yani, L. (2008). Balancing the conflicts between family and work: problems and policy in China. All-China Women's Federation, Beijing (Unpublished manuscript).

Lokshin, M., Glinskaya, E., \& Garcia, M. (2004). The effect of early childhood development programs on women's labor force participation and older children's schooling in Kenya. Journal of African Economics, 13, 240-276.

Lumsdaine, R.L. \& S.C. Vermeer. (2014). Retirement timing of women and the role of care responsibilities for grandchildren. NBER Working Paper 20756.

Mao, S., Connelly, R., \& Chen, X. (2018). Stuck in the middle: off-farm employment and caregiving of Middle-Aged Rural Chinese. Feminist Economics, 24(2), 100-121.

Maurer-Fazio, M., Connelly, R., Chen, L., \& Tang, L. (2009). Childcare, eldercare, and labor force participation of married women in Urban China, 1982-2000. Journal of Human Resources, 46(2), 261-294.

Nguyen, H. T., \& Connelly, L. B. (2014). The effect of unpaid caregiving intensity on labour force participation: Results from a multinomial endogenous treatment model. Social Science and Medicine, $100(1), 115-122$.

Posadas, J., \& M. Vidal-Fernández. (2012). Grandparents' childcare and female labor force participation. IZA DP No. 6398.

Powell, L. M. (2002). Joint labor supply and childcare choice decisions of married mothers. Journal of Human Resources, 37, 106-128. 
Quisumbing, A. R., Hallman, K., \& Ruel, M. T. (2007). Maquiladoras and market mamas: Women's work and childcare in Guatemala City and Accra. Journal of Development Studies, 43, 420-455.

Rupert, P., \& Zanella, G. (2018). Grandchildren and their grandparents' labor supply. Journal of Public Economics, 159, 89-103.

Sheng, X., \& Settles, B. (2006). Intergenerational relationships and elderly care in China. Current Sociology, 54(2), 293-313.

Song, Y., \& Dong, X.-Y. (2017). Childcare costs and migrant and local mothers' labor force participation in urban China. Feminist Economics, 1, 1-25.

Terza, J. V., Basu, A., \& Rathouz, P. J. (2008). Two-stage residual inclusion estimation: Addressing endogeneity in health econometric modeling. Journal of Health Economics, 27, 531-543.

Van Bavel, J., \& De Winter, T. (2013). Becoming a grandparent and early retirement in Europe. European Sociological Review, 29(6), 1295-1308.

Wang, Y., \& Zhang, C. (2018). Gender inequalities in labor market outcomes of informal caregivers near retirement age in urban China. Feminist Economics, (1), 1-24.

Zamarro, G. (2011). Family labor participation and child care decisions: the role of grannies. RAND Working papers WR-833.

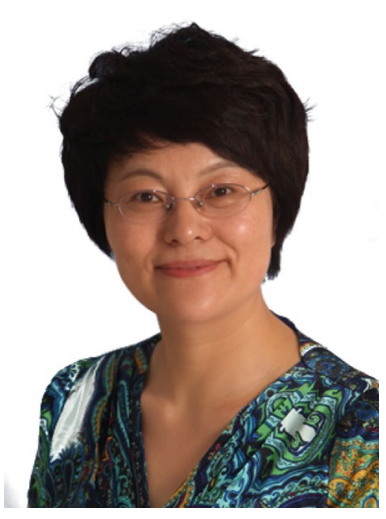

Fenglian Du is professor of Economics in School of Economics and Management, at Inner Mongolia University in China. She specializes in Labor Economics and Urbanization. Her main research interests include intergenerational transmission of income and education in the transitional China, migration and urbanization, Care economy and women's performance in labor market, and Chinese time use. She is the author of the books: "Unemployment in Urban China:Determinants and Consequences" (published by Inner Mongolia University Press in 2007), and "Where has time gone? Research report of Chinese time use survey" (published by Chinese Social Science Press in 2018). She serves as the dean of School of Economics and Management, at Inner Mongolia University in China, and the director of Chinese Time Use Survey Center at Inner Mongolia University. She organized the national representative survey of Chinese Time Use Survey (CTUS), covering 29 provinces in the mainland in 2017. She is the first prize winner of Social Science Award by Inner Mongolia Government in 2017. And she is also the winner of PRAIRIE DISTINGUSHED TALENTS Award by Inner Mongolia Government in 2011. She is the New Century Excellent Talents by Chinese Education Department in 2010.

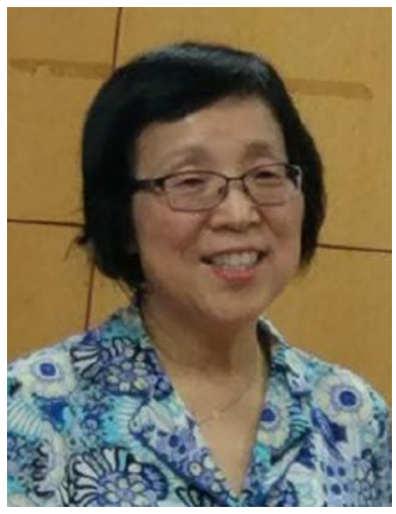

Xiao-yuan Dong is professor of Economics in Department of Economics at University of Winnipeg in Canada. She specializes in Labor Economics and Econometrics. Her main research interests include transition economy in China, labor market in China, gender equality, unpaid economy and time use. Her papers were published in the Journal of political economy, Journal of development economics, Journal of comparative economics, Economics of transition, Feminist economics. She is the co-author of the book: "Where has time gone? Research report of Chinese time use survey" (published by Chinese Social Science Press in 2018). She serves as the associate editor of "Feminist economics", and also the board member of International Association for Feminist Economics. 


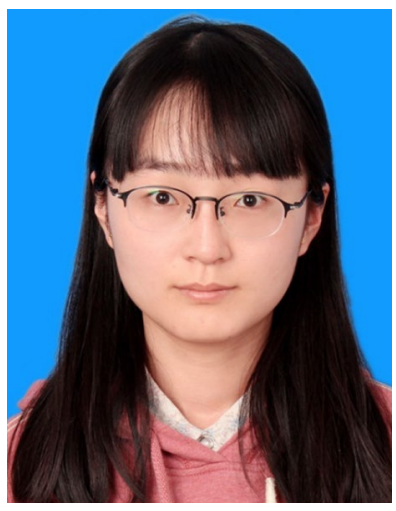

Yinyu Zhang is Ph.D. candidate at Inner Mongolian University in China. She serves as the research secretary at Chinese Time Use Survey Center at Inner Mongolia University. Her main research interests include child care, female employment, early child education and Chinese time use. 